\begin{tabular}{l} 
JOURNAL OF APPLIED SMART ELECTRICAL \\
NETWORK AND SYSTEMS (JASENS) \\
\hline ISAS
\end{tabular}

\title{
Simulasi Sistem Transfer Daya Nirkabel Berbasis Kopling Magnetik
}

\author{
Laurentius Kevin Hendinata ${ }^{1}$ \\ ${ }^{1}$ Departemen Teknik Nuklir dan Teknik Fisika, Fakultas Teknik, Universitas Gadjah Mada \\ ${ }^{1}$ kevinhendinata@mail.ugm.ac.id*
}

\begin{abstract}
Technological developments require the development of wireless power transfer systems. From the various types of technology, magnetic coupling-based wireless power transfer system is one of the most widely used technologies. This research was conducted to study and design a magnetic coupling based wireless power transfer system circuit using the Proteus 8 simulation software. This wireless power transfer system consists of a transceiver, an inductive coil, and a power receiver. Experiments have been carried out and a wireless power transfer system using inductive coupling can produce power readings in the receiver coil circuit. The measured voltage value on the receiver coil in real (not ideal) conditions indicates power losses of at least $17.1296 \%$ due to electromagnetic interference. However, this magnetic coupling based wireless power transfer system can provide charging flexibility so that it remains attractive for application in various technologies.
\end{abstract}

Keywords: wireless power transfer, magnetic coupling, inductive, simulation, proteus

\begin{abstract}
Abstrak
Perkembangan teknologi menuntut berkembangnya sistem transfer daya nirkabel. Dari berbagai jenis teknologinya, sistem transfer daya nirkabel berbasis kopling magnetik merupakan salah satu teknologi yang banyak digunakan. Penelitian ini dilakukan untuk mempelajari dan merancang rangkaian sistem transfer daya nirkabel berbasis kopling magnetik menggunakan perangkat lunak simulasi Proteus 8. Sistem transfer daya nirkabel ini tersusun atas komponen pemancar (transceiver), kumparan induktif, dan penerima daya (receiver). Percobaan telah dilakukan dan sistem transfer daya nirkabel menggunakan kopling induktif dapat menghasilkan pembacaan daya pada rangkaian kumparan penerima (receiver). Nilai tegangan terukur pada kumparan penerima (receiver) dalam kondisi nyata (tak ideal) menunjukkan adanya rugi-rugi daya paling sedikit $17,1296 \%$ akibat interferensi elektromagnetik. Namun, sistem transfer daya nirkabel berbasis kopling magnetik ini dapat memberikan fleksibilitas pengisian daya sehingga tetap menarik untuk diaplikasikan pada berbagai teknologi.
\end{abstract}

Kata kunci: transfer daya nirkabel, kopling magnetik, induktif, simulasi, proteus

Diterima Redaksi: 17-09-2021 | Selesai Revisi : 29-11-2021 | Diterbitkan Online : 31-12-2021

\section{Pendahuluan}

Perkembangan teknologi yang terjadi saat ini membawa kebutuhan akan penyediaan teknologi yang mudah dan nyaman digunakan oleh penggunanya. Tuntutan kemudahan penggunaan secara khusus pada bidang teknologi membawa dampak pada sistem yang serba nirkabel untuk mempermudah penggunaannya, termasuk salah satunya pengisian daya. Metode pengisian daya secara nirkabel ini banyak dikenal dengan metode wireless power transfer (WPT). Sistem WPT ini memungkinkan daya untuk ditransfer dari satu jaringan listrik ke jaringan lainnya tanpa memerlukan kabel atau kontak yang terbuka [1].

Berbagai konfigurasi sistem transfer daya nirkabel telah dikembangkan. Mereka berbeda dalam frekuensi operasi, efisiensi, interferensi elektromagnetik terkait (EMI), dan faktor lainnya [2]. Dari berbagai teknologi yang berkembang, sistem transfer daya induktif merupakan teknologi yang paling efisien dan paling sering digunakan pada berbagai teknologi [3]. Kinerja transmisi daya induktif ini memiliki efisiensi tinggi yang dapat mencapai 96\% [4]. Selain itu, teknologi ini memiliki ketahanan (robustness) dan keandalan (reliability) tinggi di lingkungan yang ekstrim, serta tidak terpengaruh polutan.

Teori yang mendasari kinerja sistem induktansi magnetik ini adalah terjadinya resonansi frekuensi dan nilai kuat medan magnet yang sama pada kedua kumparan (koil). Pada konfigurasi ini, kumparan pada pemancar (tranciever) akan menghasilkan fluk terhadap waktu yang menginduksi kumparan penerima (receiver) yang menimbulkan arus induksi pada kumparan kedua sehingga akan terjadi transfer daya pada kedua kumparan tersebut [5]. Namun, kinerja sistem transfer daya berbasis induktansi magnetik membutuhkan 
frekuensi yang tinggi untuk menghasilkan medan penyearah jembatan (bridge rectifier) untuk mengubah magnet (10k-10MHz) yang berpotensi menyebabkan tegangan AC dan menghasilkan tegangan keluaran DC. adanya interferensi elektromagnetik yang besar [6]. Oleh Komponen kapasitor pada keluaran penyearah jembatan karena itu, penelitian ini menganalisis seberapa besar (bridge rectifier) bertindak sebagai filter untuk interferensi elektromagnetik yang terjadi pada sistem mengurangi tegangan riak (ripple voltage) sebelum daya transfer daya ini, serta dampaknya terhadap efektivitas dialirkan ke beban.

transfer dayanya.

\section{Metode Penelitian}

Metode yang digunakan dalam penelitian ini adalah tegangan mas melakukan perancangan rangkaian sistem pengisian memberikan variasi spesifikasi induktansi magnetisasi daya nirkabel berbasis kopling magnetik dan melakukan kopling magnetik pada komponen transformator. Selain simulasi hasil perancangan dengan pemodelan pada itu, sebagai variabel pembanding, dilakukan pula perangkat lunak Proteus 8 .

Perancangan skematik pada sistem transfer daya nirkabel berbasis kopling magnetic pada umumnya 3. Simulasi dan Pembahasan digambarkan seperti pada Gambar 1.

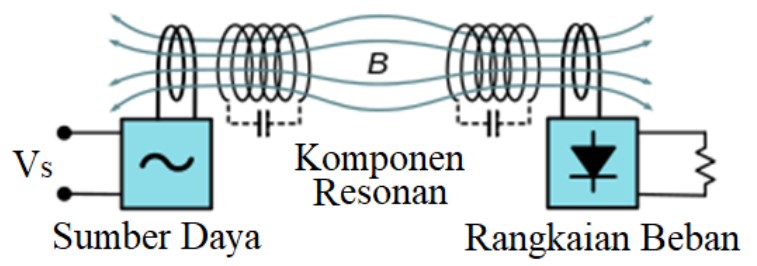

Gambar 1. Skema rangkaian sistem transfer daya nirkabel.

Skema tersebut dikembangkan menjadi suatu rangkaian utuh yang dirancang melalui perangkat lunak Proteus 8 . Untuk menyusun rangkaian ini, digunakan komponen sumber daya berupa function generator, dua buah voltmeter, dua buah amperemeter, dua buah kapasitor 10 $\mu \mathrm{F}$, satu buah kapasitor $5 \mu \mathrm{F}$, satu buah transformator dengan rasio $\mathrm{N}_{\mathrm{p}}: \mathrm{N}_{\mathrm{s}}$ sebesar 10:10, dioda bridge, sebuah hambatan beban, dan perangkat osiloskop.

Rangkaian yang dirancang pada sistem ini ditunjukkan seperti yang ditunjukkan pada Gambar 2.

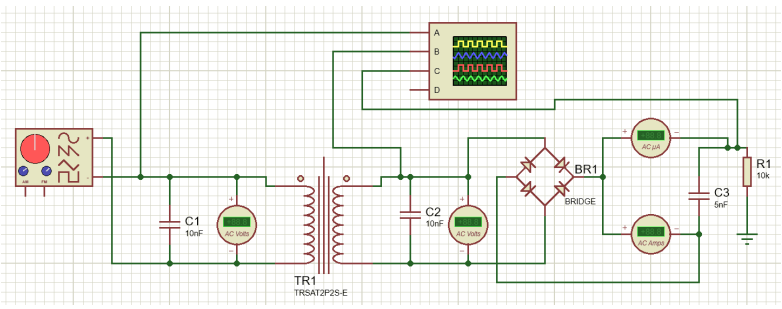

Gambar 2. Gambar 2. Rangkaian sistem transfer daya nirkabel pada perangkat lunak Proteus 8

Dalam simulasi yang dilakukan, diukur besar tegangan masukan yang berada pada rangkaian pemancar daya (transceiver) serta tegangan keluaran yang berada pada rangkaian penerima daya (receiver). Spesifikasi tegangan yang diatur pada function generator adalah 1,2 MHz. Daya yang dihasilkan ini nantinya akan ditransmisikan menuju komponen receiver secara nirkabel melalui komponen transformator, yang mana tersusun atas komponen kopling induktif. Pada rangkaian penerima daya (receiver), digunakan Journal of Applied Smart Electrical Network and Systems (JASENS)
Justifikasi efisiensi transmisi daya pada simulasi ini dilakukan dengan membandingkan nilai tegangan yang diterima pada komponen penerima (receiver) terhadap simulator dengan komponen kopling magnetik berupa transformator ideal.

Simulasi telah dilakukan untuk mendapatkan efisiensi sistem transfer daya nirkabel menggunakan perangkat lunak Proteus 8. Transformator yang digunakan dalam simulasi ini menggunakan spesifikasi komponen seperti pada Tabel 1 .

Tabel 1. Spesifikasi tranformator sebagai komponen kopling induktansi

\begin{tabular}{ll}
\hline Parameter & Nilai \\
\hline Kapasitas Fluks (V/s) & $25 \mu$ \\
Fluks Awal (Initial) (V/s) & 0 \\
Induktansi Saturasi (H) & $100 \mu$ \\
Induktansi Leakage (H) & $1 \mu$ \\
Frekuensi Arus Eddy (Hz) & $10 \mathrm{k}$ \\
Rasio Np:Ns & $10: 10$ \\
Resistansi Primer (DC) $(\Omega)$ & $100 \mathrm{~m}$ \\
Resistansi Sekunder $(\mathrm{DC})(\Omega)$ & $100 \mathrm{~m}$ \\
\hline
\end{tabular}

Berdasarkan simulasi yang dilakukan, didapatkan data simulasi dengan memberikan variasi terhadap parameter induktansi pada kumparan seperti yang ditunjukkan pada Tabel 2 .

Tabel 2. Hasil simulasi transfer daya nirkabel dengan variasi

induktansi magnetisasi

\begin{tabular}{ccc}
\hline $\begin{array}{c}\text { Induktansi } \\
\text { Magnetisasi }(\mathrm{mH})\end{array}$ & $\begin{array}{c}\text { Tegangan } \\
\text { Transceiver }(\mathrm{V})\end{array}$ & $\begin{array}{c}\text { Tegangan } \\
\text { Receiver }(\mathrm{mV})\end{array}$ \\
\hline 1 & 0,216 & 16,5 \\
2 & 0,216 & 17,2 \\
3 & 0,216 & 17,5 \\
4 & 0,216 & 17,6 \\
5 & 0,216 & 17,7 \\
6 & 0,216 & 17,8 \\
7 & 0,216 & 17,8 \\
8 & 0,216 & 17,9 \\
9 & 0,216 & 17,9 \\
10 & 0,216 & 17,9 \\
11 & 0,216 & 17,9 \\
12 & 0,216 & 17,9 \\
\hline
\end{tabular}


Hasil yang didapatkan pada Tabel 2 tersebut kemudian divisualisasikan dalam bentuk plot scatter dan didapatkan grafik seperti yang ditunjukkan pada Gambar 3.

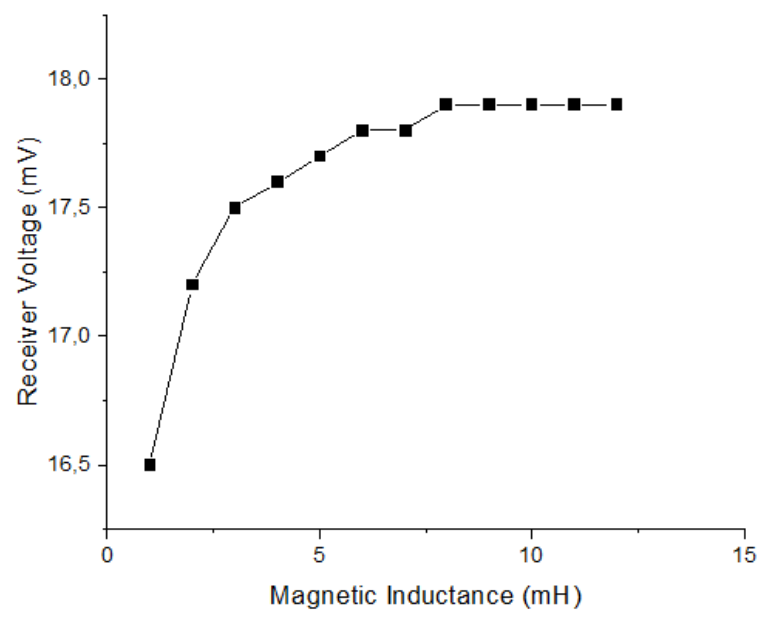

Gambar 3. Gambar 3. Grafik hasil simulasi sistem transfer daya nirkabel pada Proteus 8 dengan variasi nilai induktansi magnetisasi pada kumparan.

Berdasarkan simulasi yang dilakukan, dengan mengidentifikasi perbandingan antara tegangan terukur yang dipancarkan oleh komponen transceiver dengan tegangan terukur yang dipancarkan oleh komponen receiver, dapat ditunjukkan adanya reduksi nilai tegangan yang cukup signifikan. Reduksi nilai tegangan yang terjadi ini terjadi salah satunya oleh interferensi elektromagnetik yang besar pada sistem kopling tak ideal [7]. Besar reduksi tegangan ini ditunjukkan pada Tabel 3.

\begin{tabular}{cc} 
Tabel & 3. Kalkulasi reduksi nilai tegangan \\
\hline $\begin{array}{c}\text { Induktansi } \\
\text { Magnetisasi (mH) }\end{array}$ & $\begin{array}{c}\text { Reduksi Nilai } \\
\text { Tegangan (\%) }\end{array}$ \\
\hline 1 & 23,6111 \\
2 & 20,3704 \\
3 & 18,9815 \\
4 & 18,1395 \\
5 & 18,0556 \\
6 & 17,5926 \\
7 & 17,5926 \\
8 & 17,1296 \\
9 & 17,1296 \\
10 & 17,1296 \\
11 & 17,1296 \\
12 & 17,1296 \\
\hline
\end{tabular}

Sebagai variabel pembanding, telah dilakukan pula simulasi dengan menggunakan komponen kopling magnetik berupa transformator yang ideal dengan rasio $\mathrm{Np}: \mathrm{Ns}=10: 10$. Hasil pengukuran pada keadaan komponen transformator ideal ini ditunjukkan pada Tabel 4.
Tabel 4. Hasil simulasi sistem transfer daya nirkabel dengan transformator ideal

\begin{tabular}{ccc}
\hline $\begin{array}{c}\text { Tegangan } \\
\text { Transceiver }(\mathrm{V})\end{array}$ & $\begin{array}{c}\text { Tegangan } \\
\text { Receiver }(\mathrm{mV})\end{array}$ & $\begin{array}{c}\text { Reduksi Nilai } \\
\text { Tegangan }(\%)\end{array}$ \\
\hline 0,207 & 0,207 & 0 \\
0,208 & 0,208 & 0 \\
0,209 & 0,209 & 0 \\
0,210 & 0,210 & 0 \\
0,211 & 0,211 & 0 \\
0,212 & 0,212 & 0 \\
0,213 & 0,213 & 0 \\
0,214 & 0,214 & 0 \\
0,215 & 0,215 & 0 \\
0,216 & 0,216 & 0 \\
\hline
\end{tabular}

Hasil yang didapat dari simulasi ini memberikan nilai reduksi tegangan $0 \%$ atau efisiensi $100 \%$ jika menggunakan transformator ideal. Kondisi transformator yang ideal ini berarti tidak ada rugi-rugi daya sehingga daya masukan transfomator akan sama dengan daya keluarannya [8].

Dalam hal perancangan sistem transfer daya nirkabel ini, kondisi ideal dalam sistem sangat sulit untuk direalisasikan. Oleh karena itu, sesuai dengan hasil simulasi yang didapatkan, tegangan terukur pada rangkaian receiver pada sistem dalam kondisi tak ideal menunjukkan adanya rugi-rugi daya yang besar dibandingkan dengan kondisi idealnya. Meskipun transformasi tak ideal memberikan rugi-rugi daya yang cukup signifikan terhadap daya yang ditransmisikan, tetapi teknologi ini masih tetap memberikan performansi yang fleksibel dalam penggunaannya pada berbagai teknologi.

\section{Kesimpulan}

Simulasi sistem transfer daya berbasis kopling magnetik menggunakan perangkat lunak Proteus 8 ini menunjukkan adanya fluks magnetik pada kumparan primer sebagai komponen transceiver dan menginduksi kumparan sekunder sebagai komponen receiver. Perhitungan dalam kondisi komponen kopling magnetik berupa transformator nyata (tak ideal) menunjukkan adanya rugi daya setidaknya $17,1296 \%$ akibat interferensi elektromagnetik yang terjadi. Walaupun demikian, sistem transfer daya nirkabel berbasis kopling magnetik ini masih tetap memberikan performansi yang fleksibel dalam penggunaannya pada berbagai teknologi.

\section{Daftar Rujukan}

1] C. A. Baguley, S. G. Jayasinghe, and U. K. Madawala, "Theory and Control of Wireless Power Transfer Systems," in Control of Power Electronic Converters and Systems, F. Blaabjerg, Ed. Academic Press, 2018. doi: 10.1016/B978-0-12-816136-4.000233.

[2] C. Panchal, S. Stegen, and J. Lu, "Review of static and dynamic wireless electric vehicle charging system," Engineering Science and Technology, an International Journal, vol. 21, no. 5, pp. 922 937, Oct. 2018 
[3] M. A. Z. Abidin, W. I. Ibrahim, and M. S. Jadin, "Design of Inductive Power Transfer (IPT) for Low-Power Application.," vol. 10 , no. 21 , p. $6,2015$.

[4] R. K. Mai, B. Luo, T. Long, R. Dai, H. Zhengyou, and W. li, "Analysis and Design of Hybrid Inductive and Capacitive Wireless Power Transfer for High Power Applications," IET Power Electronics, vol. 11, Sep. 2018, doi: 10.1049/ietpel.2018.5279.

[5] A. Bachri and Z. Abidin, "Wireless Energy Transfer Magnetic Coupling Simulation," Jurnal JE-Unisla, vol. 5, no. 1, pp. 321$325,2020$.

[6] C. Xia, Y. Zhou, J. Zhang, and C. Li, "Comparison of Power Transfer Characteristics between CPT and IPT System and Mutual
Inductance Optimization for IPT System," JCP, vol. 7, no. 11, pp. 2734-2741, Nov. 2012, doi: 10.4304/jcp.7.11.2734-2741.

[7] E. Baikova, S. Valtchev, R. Melicio, A. Krusteva, and V. Pires, "Study of the Electromagnetic Interference Generated by Wireless Power Transfer Systems," International Review of Electrical Engineering (IREE), vol. 11, p. 526, Oct. 2016, doi: 10.15866/iree.v11i5.9773.

8] S. A. Mousavi, "Electromagnetic Modelling of Power Transformers for Study and Mitigation of Effects of GICs," Doctoral Thesis, Royal Institute of Technology (KTH), Swedia, 2015. 